\title{
Sensory profiles of breast meat from broilers reared in an organic niche production system and conventional standard broilers
}

\author{
Klaus Horsted, ${ }^{a *}$ Bodil H Allesen-Holm, ${ }^{b}$ John E Hermansen ${ }^{a}$ \\ and Anne G Kongsted ${ }^{\mathrm{a}}$
}

\begin{abstract}
BACKGROUND: Breast meat from broilers produced in very different production systems may vary considerable in sensory profile, which may affect consumer interests. In this study the aim was to evaluate differences in the sensory profiles of breast meat from five broiler products: two conventional standard products (A and B) and three organic niche genotypes (I657, L40 and $\mathrm{K8}$ ) reared in an apple orchard.

RESULTS: Thirteen out of 22 sensory attributes differed significantly between the products. The aroma attributes 'chicken', 'bouillon' and 'fat' scored highest and the 'iron/liver' aroma lowest for the niche products. The meat was more 'tender', 'short' and 'crumbly' and less 'hard' and 'stringy' in the standard products than in one or more of the niche products. Product 'I 657' was less 'juicy' than the rest. Products 'I 657' and 'L 40' were more 'cohesive' and tasted more 'sourish' and less of 'sweet/maize' than the standard products. The 'overall liking' score was significantly higher for the ' $\mathrm{K} \mathbf{8}^{\prime}$ ' product than for the 'Standard A' and ' $L$ 40' products. The 'overall liking' score was significantly correlated with the scores for aroma and taste of 'chicken', 'umami/bouillon', 'iron/liver' and 'fat' aroma.
\end{abstract}

CONCLUSION: The sensory profiles differed particularly between conventional standard broilers and organic niche broilers, although differences were also found between breeds. The present study indicates that aroma and taste attributes were more important for the assessors than meat 'tenderness' for the overall liking of broiler meat.

(c) 2011 Society of Chemical Industry

Keywords: aroma; eating quality; organic chicken; sensory panel; taste; texture

\section{INTRODUCTION}

In the industrialised world the dominant trend in the food sector for the past 50 years has been an increase in uniformity and efficiency in food production. Lately, however, there has been a growing countervailing trend where consumers show renewed interest in differentiated food products. This differentiation relates to e.g. animal welfare aspects and environmental, food safety and human health considerations, just as locally produced foods and sensory properties of the food are important. ${ }^{1}$ In broiler meat production, France leads the way in differentiated high-quality products, e.g. 'Bresse-chicken', 'Géline de Touraine' and broilers produced under the 'Label Rouge' concept. ${ }^{2,3}$ Most other industrialised countries have limited differentiation in high-quality broiler products.

There have only been a few studies on integrated broiler and fruit production in Denmark. The hypothesis behind these studies is that synergy effects can be achieved, since the orchard is assumed to provide a good environment for the broilers, which in turn may benefit from the poultry manure and the controlling of insect pests. ${ }^{4,5}$ However, for broilers to be used as pest controllers requires them to have an active foraging behaviour in the orchard, i.e. they need to be slow-growing as they have proven to be considerably more active in the outdoor area compared with fastgrowing broilers. ${ }^{6,7}$ In addition, slow-growing broilers are present in the orchard for longer owing to their higher slaughter age, which extends their period as pest controllers. In contrast, fast-growing broilers in the conventional broiler industry are often prone to different kinds of health problems such as dermal lesions and gait abnormalities as they have been selected for their growth capacity and consequently are slaughtered at a much younger age. ${ }^{8,9}$

The production of slow-growing broilers in an alternative production system such as an orchard may result in a product that is quite different from the conventional standard broiler. It has been suggested that the quality of meat from slow-growing broilers reared under free-range conditions, like the 'Label Rouge' production system, is more suitably destined for a speciality or gourmet market ${ }^{10,11}$ and is subsequently sold at a premium price,

\footnotetext{
Correspondence to: Klaus Horsted, Department of Agroecology, Faculty of Science and Technology, Aarhus University, PO Box 50, DK-8830 Tjele, Denmark. E-mail: Klaus.Horsted@agrsci.dk
}

a Department of Agroecology, Faculty of Science and Technology, Aarhus University, PO Box 50, DK-8830 Tjele, Denmark

b Department of Food Science-Sensory Science, Faculty of Life Sciences, University of Copenhagen, Rolighedsvej 30, 5th Floor, DK-1958 Frederiksberg C, Denmark 
which among consumers may lead to the expectation of higher meat sensory quality. ${ }^{12}$ However, very little has been published on the sensory profiling of extensively produced broilers compared with conventional mainstream broiler products. Thus the objective of the present study was to evaluate how the sensory profile of meat from slow-growing broilers produced in an integrated niche system with apple production differed from conventional standard broilers for the different genotypes.

\section{EXPERIMENTAL}

Five different broiler products (18 broilers of each) were collected from two different slaughterhouses and used in the present study. A description of the broiler products is given in Table 1. Three of the 18 broilers were randomly chosen for the final sensory assessment. The rest were used during the training sessions (see later). The five products consisted of three niche products and two conventional products. The niche production broilers were reared in an organic apple orchard and differed in breed. The conventional broilers were reared at two different farms and differed only in the amount of maize in the finishing diet ( 0 vs $15 \%$ maize). It was decided to include only males in the assessment of the niche broilers, since weight difference between male and female broilers increases with age, and sex has been found to influence the sensory evaluation of broilers close to sexual maturity. ${ }^{5}$ In contrast, conventionally produced broilers are slaughtered at a much younger age where no sex differences in relation to sensory aspects would be expected. ${ }^{13}$

\section{Sensory assessment}

The sensory assessment was made by a sensory panel with ten assessors selected according to ISO 3972:1991. ${ }^{14}$ It took place in the Sensory Laboratory of the Department of Food Science at the University of Copenhagen and consisted of a pilot study, four training sessions and the final assessment. In the pilot study a procedure for the cut-out and cooking of the breast meat was established. In addition, a preliminary set of attributes to be used at the training sessions was developed, just as recipes for reference materials were produced. The references were used to enable the panel to become familiar with the sensory attributes and to unify their perception of the specific attributes. Preliminary attributes and reference materials were decided on the basis of previous studies. ${ }^{5,15}$

\section{Cooking and serving of samples}

The frozen carcasses were thawed in a climatised chamber at $4{ }^{\circ} \mathrm{C}$ two days before the samples were served at the training or the assessment. The carcasses were filleted on the same day as they were used and trimmed so that the right and left fillets were of the same size $( \pm 2 \mathrm{~g})$. The average weight of the carcasses and trimmed breast fillets for the assessment are given in Table 1. The fillets (with skin) were cooked in preheated fan ovens at $180^{\circ} \mathrm{C}$ to a core temperature of $75^{\circ} \mathrm{C}$. The cooking time was calculated on the basis of the weight and height of the fillets. The fillets were served on a $60^{\circ} \mathrm{C}$ hot plate $2 \mathrm{~min}$ after they were cooked, i.e. the samples were warm at serving. The right and left fillets from a broiler were cut into five slices each (a sample), one for each of the ten assessors. At the training and the assessment it was ensured that each assessor on the panel received the same section of the fillet for each assessment. ${ }^{16}$ The end pieces were not used. For the assessment it was decided that the samples should be cut transversely from one end and the first cut surface used in relation to the aroma attributes. The next cut of the sample was used for assessing the texture, while the taste was assessed on a cut from the middle of the sample (Fig. 1). Between each assessment the panellists cleared the palate using cucumber, crispbread with a neutral flavour and finally water.

\begin{tabular}{|c|c|c|c|c|c|}
\hline \multirow[b]{2}{*}{ Product name } & \multicolumn{3}{|c|}{ Niche production system (organic apple orchard) } & \multicolumn{2}{|c|}{ Conventional production system } \\
\hline & 1657 & L40 & K8 & Standard A & Standard B \\
\hline Genotype & Hubbard 1657 & Bresse L40 & Kosmos 8 Red & Ross 308 & Ross 308 \\
\hline $\begin{array}{l}\text { Commercial prepared } \\
\text { feed (granulate or } \\
\text { pelleted) }\end{array}$ & $\begin{array}{l}\text { Organic ( } 20 \% \text { maize, } \\
\text { no animal feed } \\
\text { ingredients) }\end{array}$ & $\begin{array}{l}\text { Organic ( } 20 \% \text { maize, } \\
\text { no animal feed } \\
\text { ingredients) }\end{array}$ & $\begin{array}{l}\text { Organic ( } 20 \% \text { maize, } \\
\text { no animal feed } \\
\text { ingredients) }\end{array}$ & $\begin{array}{l}\text { Conventional (no } \\
\text { maize, no animal } \\
\text { feed ingredients) }\end{array}$ & $\begin{array}{l}\text { Conventional ( } 15 \% \\
\text { maize, no animal } \\
\text { feed ingredients) }\end{array}$ \\
\hline $\begin{array}{l}\text { Supplementary whole } \\
\text { wheat }\end{array}$ & No & No & No & $\begin{array}{l}\text { Increasing from } 7 \text { to } \\
38 \text { days of age } \\
(5-30 \%)\end{array}$ & $\begin{array}{l}\text { Increasing from } 7 \text { to } \\
38 \text { days of age } \\
\text { (3-27\%) }\end{array}$ \\
\hline Outdoor area & $\begin{array}{l}9 \mathrm{~m}^{2} \text { per broiler } \\
\text { (orchard) }\end{array}$ & $\begin{array}{l}9 \mathrm{~m}^{2} \text { per broiler } \\
\text { (orchard) }\end{array}$ & $\begin{array}{l}9 \mathrm{~m}^{2} \text { per broiler } \\
\text { (orchard) }\end{array}$ & No & No \\
\hline Sex & Male & Male & Male & Mixed & Mixed \\
\hline Age at slaughter (days) & 82 & 82 & 82 & 38 & 38 \\
\hline $\begin{array}{l}\text { Average carcass weight } \\
\text { at assessment } \\
\text { (g) }(n=3)\end{array}$ & 1958 & 1550 & 2320 & 1597 & 1595 \\
\hline $\begin{array}{l}\text { Average weight of } \\
\text { trimmed breast fillets } \\
\text { at assessment } \\
\text { (g) }(n=6)\end{array}$ & 214 & 148 & 234 & 207 & 207 \\
\hline Slaughterhouse & $\begin{array}{l}\text { Small } \\
\text { slaughterhouse, } \\
\text { organic } \\
\text { certification }\end{array}$ & $\begin{array}{l}\text { Small } \\
\text { slaughterhouse, } \\
\text { organic } \\
\text { certification }\end{array}$ & $\begin{array}{l}\text { Small } \\
\text { slaughterhouse, } \\
\text { organic } \\
\text { certification }\end{array}$ & $\begin{array}{l}\text { Industrial poultry } \\
\text { slaughterhouse }\end{array}$ & $\begin{array}{l}\text { Industrial poultry } \\
\text { slaughterhouse }\end{array}$ \\
\hline
\end{tabular}


The end pieces of the fillets were not used

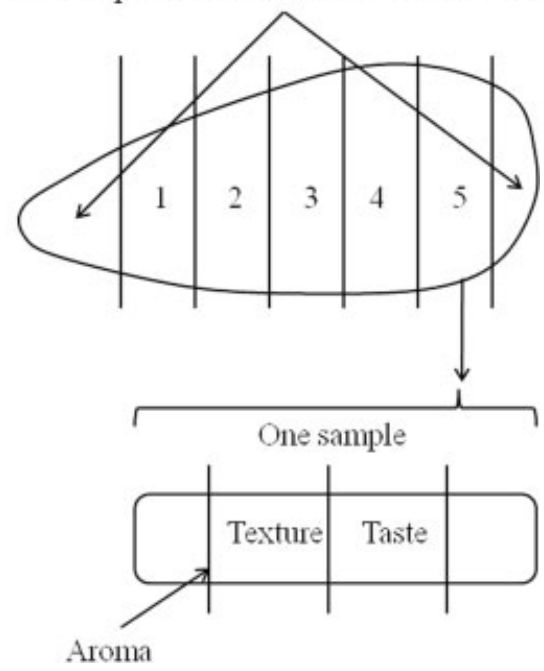

Figure 1. Illustration of cutting of breast fillets and samples. Five samples were cut from each breast fillet.

\section{Sensory method}

The four training sessions took place on four successive days and were guided by a panel leader (not a member of the panel). Only the panel leader knew which samples were served during the training sessions and the final assessment. At the first training session the procedure relating to 'smelling', 'biting' and 'tasting' was introduced and the assessors were informed about the preliminary attributes and reference materials. Subsequently the assessors were presented with six samples in three pairs. The samples were served in a sensory evaluation laboratory accommodated to meet the demands in ISO 8589:1988 ${ }^{17}$ and ASTM STP $913 .{ }^{18}$ The differences and similarities between the samples in relation to the set of attributes were discussed in plenum. As a result of the first training session, some of the attributes from the pilot study were changed, just as new words were added to the list, e.g. the taste of 'umami' was changed to 'umami/bouillon' and, under the texture attributes, 'elastic-like' and 'short' were added. On the second day of training the panel was presented initially with four samples in pairs, which were discussed in plenum. Subsequently four new samples were served, but this time the assessors were placed in separate booths with no contact with each other. The same procedure was followed on the third day, but with four samples in pairs discussed in plenum and five samples served in the booths. At this session it was decided that the texture attributes 'hardness', 'elastic-like', 'tenderness' and 'juiciness' should be evaluated at the fourth chew, whereas 'short', 'crumbly', 'stringy' and 'cohesive' should be evaluated when the sample was ready for swallowing. On the fourth day of training the assessors were presented with a sample pair, for which they were told to focus mainly on texture attributes, which were discussed afterwards. Finally, the assessors were presented with 12 samples in the booths. After the final discussion, no changes were made in the set of attributes presented in Table 2. All changes during the training sessions were decided only by the assessors without any influence by the panel leader.

The assessment took place on three successive days and each broiler product was served on each day, i.e. three replications were used. The serving order on each day was randomised by a Latin-square method. ${ }^{16,19}$ The assessors were placed in separate booths and, for each sample, each attribute was evaluated on a $15 \mathrm{~cm}$ unstructured line scale, with 15 as the highest score and 0 as the lowest. The anchor points for all attributes were 'none' on the left side and 'extreme' on the right side. ${ }^{19-21}$ Data were collected electronically using FIZZ Network Acquisition Version $2.40 \mathrm{E}^{22}$ In addition to the objective assessment of attributes, the assessors were asked to give a subjective preference score of 'overall liking' for each sample assessment of the products.

\section{Statistical methods}

For the statistical analysis, 'PROC MIXED' in SAS Version $9.1^{23}$ was used. The analysis included five products, i.e. three niche products (1657, L40 and K8) and two conventional standard products (Standards A and B). In the statistical model, 'product' was defined as a fixed effect and 'replication', 'assessor', 'replication $\times$ assessor' and 'replication $\times$ product' were random effects. Data were found to be normally distributed. The sensory data were additionally subjected to principal component analysis (PCA) using PanelCheck Version 1.2.1. ${ }^{24}$ This program was also used for the detection of outliers in the raw data. In addition, a calculation of PCA models in the program FIZZ Calculation was used as a guideline for outlier removal. ${ }^{22}$ One assessor had difficulties with one attribute and another assessor with two. In these cases, data were replaced by the average for the rest of the panel as suggested by Hoo et al. ${ }^{25}$

\section{RESULTS}

To visualise relationships between attributes and the products tested, results from the PCA are given in Figs 2 and 3. Terms close together are related. Terms far away from each other are different. Principal component 1 (PC1) is the horizontal axis in both figures and is the main source of variance with an explained variance of $85.2 \%$. Principal component 2 (PC2) is the vertical axis in Fig. 2 and principal component 3 (PC3) is the vertical axis in Fig. 3. As indicated by Figs 2 and 3, there is a huge difference in the sensory profile between especially the standard and the niche products, being on opposite sides of the PC1 axis. Even though Fig. 2 indicates a large vertical difference (PC2) between 'I 657' and ' $\mathrm{L} 40^{\prime}$ and Fig. 3 indicates a large difference (PC3) between ' 1657 ' and ' $\mathrm{K} 8$ ', the explained variance is only 7.8 and $4.4 \%$ for PC2 and PC3 respectively. Thus the differences between the standard products and the niche products are much more pronounced than the differences between the niche products themselves.

Results from the analysis of variance are given in Table 3. Aroma attributes differed significantly for four out of seven attributes between types of chicken product. The positive aroma attributes 'chicken' and 'bouillon' were significantly more pronounced in 'I 657 ' and ' $\mathrm{K} 8$ ' than in the standard products, and 'bouillon' scored significantly higher in ' $L 40$ ' than in 'Standard A'. The score for the negative attribute 'iron/liver' was significantly lower for ' 1657 ' and ' $\mathrm{K} 8$ ' than for the other products. In addition, the two standard products had a significantly less pronounced aroma of the neutral attribute 'fat' than the niche products.

Seven out of eight texture attributes were found to differ significantly among products $(P<0.05)$, and the 'elastic-like' attribute indicated a tendency for being less pronounced in the standard products $(P=0.06)$. The meat was found to be significantly harder (negative attribute) in 'I 657' than in the standard products, just as ' $\mathrm{K} 8$ ' was harder than 'Standard A'. 
Table 2. Final reference schedule used for sensory assessment

Aroma

1. Chicken (positive)

2. $\quad$ Neck of pork (negative)

3. Sourish (negative)

4. Sweet/maize (positive)

5. Bouillon (positive)

6. Iron/liver (negative)

$7 . \quad$ Fat (neutral)

Texture

8.

9.

10.

11.

12.

13.

14.

15.

Taste

16.

17.

18.

19.

20.

21.

22.
Hardness (negative)

'Elastic-like' (negative)

Tenderness (positive)

Juiciness (positive)

Short (neutral)

Crumbly (negative)

Stringy (neutral)

Cohesive (neutral)

Chicken (positive)

Neck of pork (negative)

Sourish (negative)

Sweet/maize (positive)

Umami/bouillon (positive)

Iron/liver (negative)

Fat (neutral)
How strong is the positive aroma of fresh chicken meat?

How strong is the aroma of neck of pork?

How strong is the sourish aroma?

How strong is the aroma of sweetish maize?

How strong is the aroma of chicken bouillon?

How strong is the aroma of iron/liver?

How strong is the aroma of fat?

How hard is the sample up to the fourth chewing?

How 'elastic-like' is the sample up to the fourth chewing?

How tender is the sample up to the fourth chewing?

How juicy is the sample up to the fourth chewing?

How short does the meat structure feel when ready for swallowing?

How crumbly is the sample when ready for swallowing?

How stringy is the sample when ready for swallowing?

How cohesive is the sample when ready for swallowing?

How strong is the taste of fresh chicken meat?

How strong is the taste of neck of pork?

How sourish does the sample taste?

How strong is the taste of sweetish maize?

How strong is the taste of umami/bouillon?

How strong is the taste of iron/liver?

How strong is the taste of fat?
The standard products had a significantly higher score for the positive attribute 'tenderness' than the niche products, although ' $\mathrm{L} 40$ ' only differed significantly from 'Standard A'. For the positive attribute 'juiciness', 'I 657' was significantly less juicy than the other products. The assessors found that the meat structure felt significantly 'shorter' (neutral) in the standard products, just as these were less 'stringy' (neutral). The negative attribute 'crumbly' was significantly more pronounced in the 'Standard $\mathrm{B}^{\prime}$ ' product than in 'I 657' and ' $\mathrm{L} 40$ ', and ' $\mathrm{L} 40$ ' was less 'crumbly' than 'Standard $\mathrm{A}^{\prime}$. The assessors found the standard products significantly less cohesive (neutral) than the niche products, except for ' $\mathrm{K} 8$ ' that only differed significantly in relation to 'Standard A'.

The taste attributes differed significantly between products in relation to the negative attribute 'sourish' and the positive attribute 'sweet/maize'. Thus 'I 657' was significantly more 'sourish' than ' $\mathrm{K} 8$ ' and the two standard products, ' $\mathrm{L} 40^{\prime}$ ' significantly more 'sourish' than the standard products, and ' $\mathrm{K} 8$ ' more 'sourish' than 'Standard $A^{\prime}$. The standard products tasted significantly more of 'sweet/maize' than 'I 657' and 'L40', whereas 'K 8' only tasted significantly less of 'sweet/maize' in relation to 'Standard $A$ '.

In relation to the subjective 'overall liking' category, the assessors gave a higher score for the ' $\mathrm{K} 8$ ' product. This was statistically significant in relation to the ' $L 40$ ' and 'Standard $A$ ' products. An indication of which attributes mainly influenced 'overall liking' can be found in Table 4, where significant correlations between 'overall liking' and sensory attributes are given. The attributes given in Table 4 are related to the aroma and taste of the products, whereas no texture attributes were significantly correlated with 'overall liking'.

\section{DISCUSSION}

Several factors such as breed, age at slaughter, diet, outdoor access and housing conditions were very different between the niche and standard broilers in the present study, which resulted in very different sensory profiles of these products as indicated by Figs 2 and 3 . In contrast, Fanatico et al. ${ }^{26}$ found that a sensory panel was able to detect only very few significant differences in the sensory profiles between slow- and fast-growing broilers reared in production systems with or without outdoor access. However, the fast-growing broilers in that study were slaughtered at 63 days of age, whereas in our study the fast-growing broilers (Standards $A$ and $B$ ) were slaughtered at 38 days of age. Other studies have shown that poultry meat characteristics are influenced by factors such as age, ${ }^{15,27}$ feed $^{28}$ and genotype, with the latter covering e.g. growth rate, body composition and locomotor activity. $6,15,29-32$ In the present study especially the texture attributes were significantly influenced as a consequence of the very different production characteristics of the standard and niche products. The fact that the breast meat from the standard broilers is tenderer with a 'shorter' fibre structure is consistent with other studies showing that younger birds have tenderer meat. ${ }^{33,34}$ However, some studies on slow-growing broilers indicate that certain breeds can have a different development in meat tenderness when age at slaughter is close to sexual maturity. 5,15

Sexual maturation has been suggested also to affect the flavour of the broiler meat by enhancing it to its maximum during the process. ${ }^{33-35}$ Six out of 13 aroma and taste characteristics were found to differ significantly in our study. Based on the carcass weight, two of the niche-produced broilers in the present study, 'I 657' and 'K8', had likely reached sexual maturity. This might explain why the niche product ' $L 40$ ' did not receive quite the same 


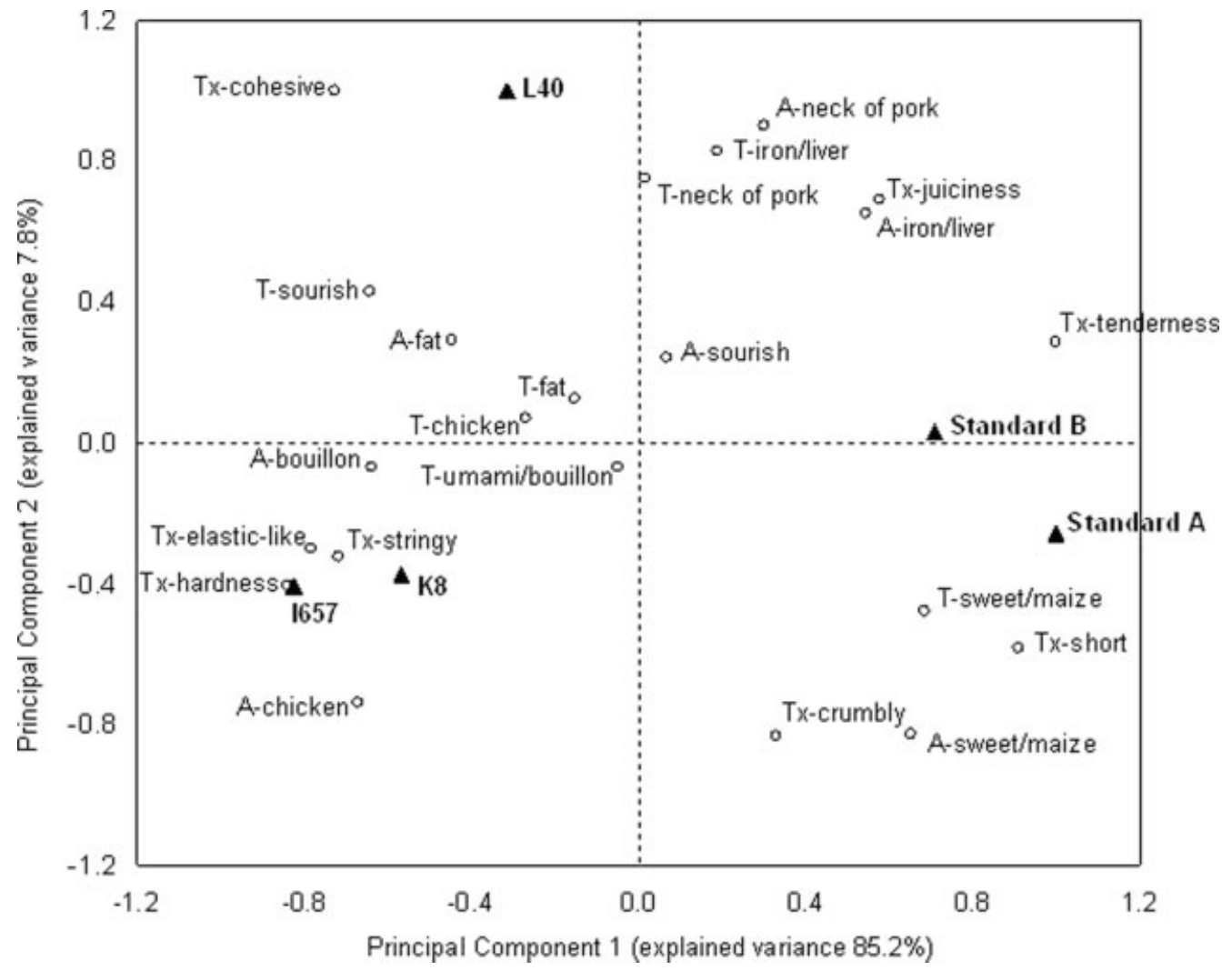

Figure 2. PCA correlation loadings plot of principal component 1 versus principal component 2: $\mathbf{\Lambda}$, product names; $\mathrm{O}$, attributes $(A$, aroma; $T x$, texture; $\mathrm{T}$, taste).

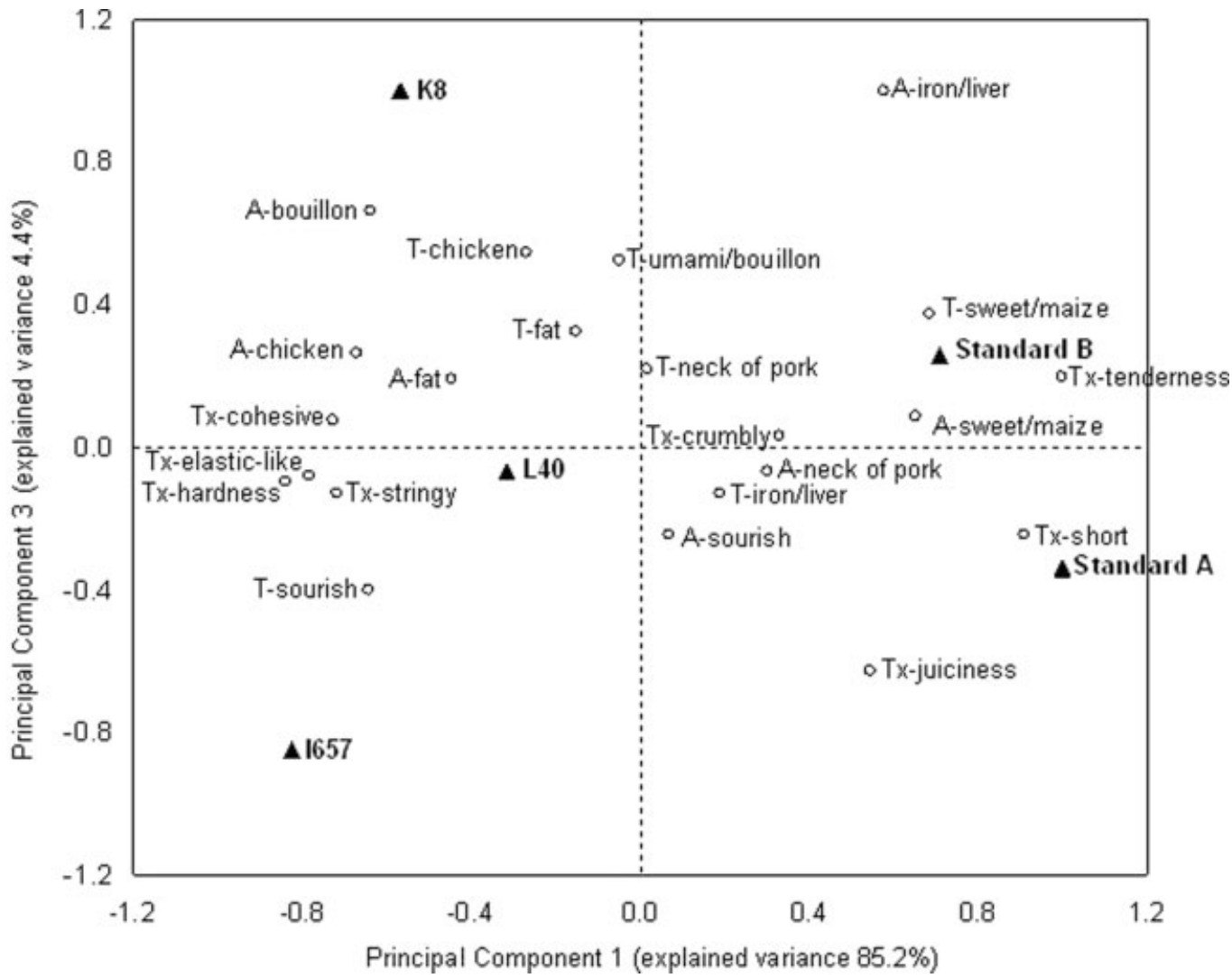

Figure 3. PCA correlation loadings plot of principal component 1 versus principal component 3 : $\mathbf{\Lambda}$, product names; $O$, attributes $(A$, aroma; $T x$, texture; $\mathrm{T}$, taste). 
Table 3. Scores as least square means, standard error of mean (SEM) and significance for aroma, texture and taste attributes

\begin{tabular}{|c|c|c|c|c|c|c|c|}
\hline \multirow[b]{2}{*}{ Attribute } & \multicolumn{5}{|c|}{ Broiler products } & \multirow[b]{2}{*}{ SEM } & \multirow[b]{2}{*}{ Significance $(P$} \\
\hline & 1657 & L40 & K8 & Standard A & Standard B & & \\
\hline \multicolumn{8}{|l|}{ Aroma attributes } \\
\hline Chicken (positive) & $9.7 a$ & 7.9ab & $9.9 a$ & $6.2 b$ & $7.3 b$ & 0.70 & $<0.05$ \\
\hline Neck of pork (negative) & 2.8 & 4.5 & 3.3 & 4.9 & 5.1 & 0.99 & NS \\
\hline Sourish (negative) & 4.4 & 4.1 & 3.5 & 4.4 & 4.4 & 0.66 & NS \\
\hline Sweet/maize (positive) & 4.7 & 4.7 & 5.6 & 8.6 & 7.1 & 1.12 & NS \\
\hline Bouillon (positive) & $6.8 \mathrm{a}$ & $6.2 \mathrm{ac}$ & $7.8 \mathrm{a}$ & $3.9 b$ & $4.4 \mathrm{bc}$ & 0.77 & $<0.01$ \\
\hline Iron/liver (negative) & $3.2 b$ & $4.9 a$ & $2.5 b$ & $6.5 a$ & $5.5 a$ & 0.76 & $<0.05$ \\
\hline Fat (neutral) & $3.4 a$ & $3.4 a$ & $3.5 a$ & $2.3 b$ & $2.3 b$ & 0.51 & 0.05 \\
\hline \multicolumn{8}{|l|}{ Texture attributes } \\
\hline Hardness (negative) & $6.0 \mathrm{a}$ & $3.8 \mathrm{ab}$ & $4.8 \mathrm{ac}$ & $1.3 b$ & $2.0 \mathrm{bc}$ & 0.96 & $<0.05$ \\
\hline 'Elastic-like' (negative) & 4.8 & 3.1 & 3.9 & 1.1 & 1.5 & 0.96 & 0.06 \\
\hline Tenderness (positive) & $6.9 b$ & $9.7 \mathrm{bc}$ & $8.4 b$ & $12.8 \mathrm{a}$ & $12.0 \mathrm{ac}$ & 0.96 & $<0.01$ \\
\hline Juiciness (positive) & $7.0 \mathrm{~b}$ & $9.0 \mathrm{a}$ & $8.6 a$ & $9.2 \mathrm{a}$ & $10.1 \mathrm{a}$ & 0.67 & 0.01 \\
\hline Short (neutral) & $6.1 b$ & $6.4 b$ & $6.0 \mathrm{~b}$ & $11.3 a$ & $11.2 \mathrm{a}$ & 1.05 & $<0.01$ \\
\hline Crumbly (negative) & $5.7 b c$ & $4.9 \mathrm{~b}$ & $6.1 \mathrm{ab}$ & 7.7ac & $8.1 \mathrm{a}$ & 0.82 & $<0.05$ \\
\hline Stringy (neutral) & $5.1 \mathrm{a}$ & $3.7 a$ & $4.4 a$ & $1.6 \mathrm{~b}$ & $1.6 b$ & 0.69 & $<0.01$ \\
\hline Cohesive (neutral) & $7.0 \mathrm{a}$ & $7.6 a$ & $6.4 \mathrm{ac}$ & $3.0 \mathrm{~b}$ & $4.4 \mathrm{bc}$ & 0.88 & $<0.01$ \\
\hline \multicolumn{8}{|l|}{ Taste attributes } \\
\hline Chicken (positive) & 8.8 & 8.4 & 9.2 & 8.7 & 7.6 & 0.61 & NS \\
\hline Neck of pork (negative) & 3.1 & 3.9 & 3.0 & 3.1 & 2.9 & 0.78 & NS \\
\hline Sourish (negative) & $8.1 \mathrm{a}$ & $7.5 \mathrm{ab}$ & $6.6 \mathrm{bd}$ & $5.0 c$ & $5.7 \mathrm{~cd}$ & 0.62 & $<0.01$ \\
\hline Sweet/maize (positive) & $2.5 b$ & $2.8 \mathrm{~b}$ & $3.9 \mathrm{bc}$ & $7.8 \mathrm{a}$ & $6.0 \mathrm{ac}$ & 0.90 & $<0.01$ \\
\hline Umami/bouillon (positive) & 4.8 & 5.0 & 5.4 & 4.4 & 5.0 & 0.70 & NS \\
\hline Iron/liver (negative) & 5.2 & 6.4 & 4.7 & 6.1 & 6.3 & 0.72 & NS \\
\hline Fat (neutral) & 2.2 & 2.0 & 2.4 & 2.0 & 1.9 & 0.47 & NS \\
\hline \multicolumn{8}{|l|}{ Liking } \\
\hline Overall liking & $6.1 \mathrm{ab}$ & $5.0 \mathrm{~b}$ & $7.8 \mathrm{a}$ & $4.2 b$ & $6.1 \mathrm{ab}$ & 0.72 & $<0.05$ \\
\hline
\end{tabular}

\begin{tabular}{|c|c|c|c|c|c|}
\hline \multicolumn{3}{|c|}{ Positive correlations } & \multicolumn{3}{|c|}{ Negative correlations } \\
\hline Attribute & Coefficient & Significance $(P)$ & Attribute & Coefficient & Significance $(P)$ \\
\hline Aroma, chicken & 0.800 & $<0.001$ & Aroma, iron/liver & -0.676 & $<0.01$ \\
\hline Taste, chicken & 0.796 & $<0.001$ & Taste, iron/liver & -0.569 & $<0.05$ \\
\hline Taste, umami/bouillon & 0.691 & $<0.01$ & Aroma, neck of pork & -0.497 & 0.06 \\
\hline Aroma, bouillon & 0.643 & $<0.01$ & & & \\
\hline Aroma, fat & 0.528 & $<0.05$ & & & \\
\hline
\end{tabular}

positive score as the other niche products, as it was considerably slower-growing and had probably not reached sexual maturity. However, it should also be borne in mind that this breed was given the same feed type as the other niche broilers, and, owing to its slower growth, this breed might have had different dietary requirements. Interactions between feed and breed in relation to sensory attributes of breast meat have been found in another study. ${ }^{15}$ The 'Bresse-chicken' is a broiler product produced in France and uses a similar breed to ' $\mathrm{L} 40$ '. It is known to be produced with special consideration to the feed allocated and has to have access to an outdoor area with vegetation. This together with the processing of the carcass produces broiler products with reputable meat qualities. ${ }^{2}$
As indicated by Figs 2 and 3, the positive attributes 'tenderness' and taste of 'sweet/maize' were positively correlated. The highest score for these attributes was given to the 'Standard A' product and was significantly different from the niche products. However, the panellists gave the lowest 'overall liking' score to the 'Standard A' product and the highest to the ' $\mathrm{K} 8$ ' product. This is in contrast to a study by Brown et al., ${ }^{36}$ where a sensory panel gave a significantly higher score for 'flavour liking' for a retailed standard product compared with retailed broilers produced under free-range or organic conditions, despite the fact that they could detect no differences in the two flavour attributes, 'chicken' and 'abnormal' flavour. In our study the attributes that were significantly correlated with 'overall liking' were the aroma and taste of 'chicken', 'iron/liver' 
and 'bouillon (umami/bouillon)' (Table 4). The positive attributes aroma and taste of 'chicken' and 'bouillon (umami/bouillon)' are, in turn, closely correlated with the ' $\mathrm{K} 8$ ' product, whereas the negative aroma and taste of 'iron/liver' is not (Figs 2 and 3). Thus the ' $\mathrm{K} 8$ ' product was given the most favourable scores for these attributes compared with the other products, even though only significantly different for aroma as indicated by Table 3. Surprisingly, 'tenderness' did not seem to be the most important attribute when scoring the liking for the different products. However, all products were given relatively high scores for 'tenderness', i.e. the meat was not considered as 'tough' in any of the cases, despite significant differences. In fact, it may be hypothesised that meat actually can be too tender, even though it is considered a positive attribute.

In this context it should be realised that a sensory panel is not comparable to a consumer preference study, since the assessors in our study were selected according to the $\mathrm{ISO}^{14}$ and completed a thorough training course to define product attributes and to unify their perception of the specific attributes. ${ }^{37}$ However, normally only relatively few product traits such as 'appearance', 'texture', 'flavour' and 'juiciness' are assessed in consumer studies, and texture and tenderness, in particular, seem to be crucial consumer attributes. Therefore a consumer test might have achieved liking scores not comparable to those in the present study. Thus consumers often prefer the things they are familiar with, and it has been suggested that long-term exposure to conventional broiler meat may be an obstacle to the liking of meat from other broiler products. ${ }^{38}$ However, a study by Ponte et al. ${ }^{39}$ indicates that, even for a 30-person consumer panel, meat tenderness may not be the only important attribute when differences in overall liking are to be found. In addition, other factors such as geographical and cultural origins of the consumer can be expected to influence consumer preference for different qualities of food products, ${ }^{40}$ just as other quality dimensions such as locally produced food, animal welfare, environment, etc. may influence consumer perception. ${ }^{1}$

In conclusion, there was a huge difference in the sensory profile of breast meat between the niche and standard broilers in our study, just as we found a small difference between the genotypes used in the niche system. The significant correlations between 'overall liking' and the aroma and taste of 'chicken', 'umami/bouillon' and 'iron/liver' indicate that differences in meat tenderness may not be the most important attribute for overall liking of broiler meat products, since broiler breast meat in general is considered as tender.

In future studies there is a need to generate more information on the sensory profile of thigh and drumstick, since higher kinetic activity in slow-growing broilers might influence the sensory profile of especially the leg muscles as a consequence of different muscle structures.

\section{REFERENCES}

1 Yiridoe EK, Bonti-Ankomah S and Martin RC, Comparison of consumer perceptions and preference toward organic versus conventionally produced foods: a review and update of the literature. Renew Agric Food Syst 20:193-205 (2005).

2 Verrier E, Tixier-Boichard M, Bernigaud B and Naves M, Conservation and value of local livestock breeds: usefulness of niche products and/or adaptation to specific environments. Anim Genet Resour Inform 36:21-31 (2005).

3 Baéza E, Chartrin P, Meteau K, Bordeau T, Juin H, Le Bihan-Duval E, et al, Effect of sex and genotype on carcass composition and nutritional characteristics of chicken meat. BrPoultry Sci 51:344-353 (2010).
4 Pedersen $\mathrm{HL}$, Olsen $\mathrm{A}$, Horsted $\mathrm{K}$, Korsgaard $\mathrm{M}$ and Pedersen $\mathrm{B}$, Combined production of broilers and fruits. 11th Int. Conf. on Cultivation Technique and Phytopathological Problems in Organic Fruit-growing, Weinsberg, pp. 131-136 (2004).

5 Horsted K, Henning J and Hermansen JE, Growth and sensory characteristics of organically reared broilers differing in strain, sex and age at slaughter. Acta Agric Scand 55:149-157 (2005).

6 Nielsen BL, Thomsen MG, Sørensen P and Young JF, Feed and strain effects on the use of outdoor areas by broilers. Br Poultry Sci 44:161 - 169 (2003).

7 Dal Bosco A, Mugnai C, Sirri F, ZampariniC and Castellini C, Assessment of a global positioning system to evaluate activities of organic chickens at pasture. J Appl Poultry Res 19:213-218 (2010).

8 Sørensen P, Su G and Kerstin SC, Effects of age and stocking density on leg weakness in broiler chickens. Poultry Sci 79:864-870 (2000).

9 Bokkers EAM and Koene $\mathrm{P}$, Behaviour of fast- and slow-growing broilers to 12 weeks of age and the physical consequences. Appl Anim Behav Sci 81:59-72 (2003).

10 Lewis PD, Perry GC, Farmer LJ and Patterson RLS, Responses of two genotypes of chicken to the diets and stocking densities typical of UKand 'Label Rouge' production systems: I. Performance, behaviour and carcass composition. Meat Sci 45:501-516 (1997).

11 Westgren RE, Delivering food safety, food quality, and sustainable production practices: the Label Rouge poultry system in France. Am J Agric Econ 81:1107-1111 (1999).

12 Harper GC and Makatouni A, Consumer perception of organic food production and farm animal welfare. BrFood J 104:287-299 (2002).

13 Poste LM, Butler G, Cave NA and Burrows VD, Sensory analysis of meat from broiler chickens fed diets containing hulless oats (Avena nuda). Can J Anim Sci 76:313-319 (1996).

14 ISO, Sensory Analysis-Methodology-Method of Investigating Sensitivity of Taste. ISO 3972:1991 (E), International Organization for Standardization, Geneva (1991).

15 Horsted K, Allesen-Holm BH and Hermansen JE, The effect of breed and feed-type on the sensory profile of breast meat in male broilers reared in an organic free-range system. Br Poultry Sci 51:515-524 (2010).

16 ASTM, Standard Guide for Serving Protocol for Sensory Evaluation of Foods and Beverages. ASTM E1871-06, American Society for Testing and Materials, West Conshohocken, PA (2006).

17 ISO, Sensory Analysis - General Guidance for the Design of Test Rooms. ISO 8589: 1988 (E), International Organization for Standardization, Geneva (1988).

18 ASTM, Physical Requirements. Guidelines for Sensory Evaluation Laboratories. ASTM STP 913, American Society for Testing and Materials, West Conshohocken, PA (1986).

19 ISO, Sensory Analysis-General Guidance for Establishing a Sensory Profile. ISO 13299:2003 (E), International Organization for Standardization, Geneva (2003).

20 ISO, Sensory Analysis-General Guidance for the Selection, Training and Monitoring of Assessors. ISO 8586-1:1993 (E), International Organization for Standardization, Geneva (1993).

21 Meilgaard M, Civille GV and Carr BT, Measuring responses, in Sensory Evaluation Techniques (4th edn), ed. by. CRC Press, Boca Raton, FL, pp. 43-57 (2007).

22 Biosystèmes, FIZZ Software Solution for Sensory Analysis and Consumer Tests [Online]. Available: http://www.biosystemes.com/datacollection,fizz-network.php [1 October 2010].

23 Littell RC, Milliken GA, Stroup WW and Wolfinger RD, SAS System for Mixed Models. SAS Institute, Cary, NC (1996).

24 Matforsk AS, The PanelCheck Project [Online]. Available: http://www.panelcheck.com/ [1 October 2010].

25 Hoo KA, Tvarlapati KJ, Piovoso MJ and Hajare R, A method of robust multivariate outlier replacement. Comput Chem Eng 26:17-39 (2002).

26 Fanatico AC, Pillai PB, Emmert JL, Gbur EE, Meullenet JF and Owens CM, Sensory attributes of slow- and fast-growing chicken genotypes raised indoors or with outdoor access. Poultry Sci 86:2441 - 2449 (2007)

27 Sonaiya EB, Ristic M and Klein FW, Effect of environmental temperature, dietary energy, age and sex on broiler carcase portions and palatability. Br Poultry Sci 31:121-128 (1990).

28 Lyon BG, Smith DP, Lyon CE and Savage EM, Effects of diet and feed withdrawal on the sensory descriptive and instrumental profiles of broiler breast fillets. Poultry Sci 83:275-281 (2004). 
29 Ricard FH, Leclercq B and Touraille C, Selecting broilers for low and high abdominal fat: distribution of carcass fat and quality of meat. BrPoultry Sci 24:511-516 (1983).

30 Chambers JR, Fortin A, Mackie DA and Larmonde E, Comparison of sensory properties of meat from broilers of modern stocks and experimental strains differing in growth and fatness. Can Inst Food Sci Technol J 22:353-358 (1989).

31 Lei S and Van Beek G, Influence of activity and dietary energy on broiler performance, carcase yield and sensory quality. Br Poultry Sci 38:183-189 (1997).

32 Dyubele NL, Muchenje V, Nkukwana $T$ and Chimonyo $M$, Consumer sensory characteristics of broiler and indigenous chicken meat: a South African example. Food Qual Prefer 21: 818-819 (2010).

33 Touraille C, Kopp J, Valin C and Ricard FH, Chicken meat quality. 1. Influence of age and growth rate on physico-chemical and sensory characteristics of the meat. Arch Geflügelkd 45:69-76 (1981).

34 Touraille C, Ricard FH, Kopp J, Valin C and Leclercq B, Chicken meat quality. 2. Changes with age of some physico-chemical and sensory characteristics of the meat. Arch Geflügelkd 45:97-104 (1981).
35 Yang $\mathrm{N}$ and Jiang R-S, Recent advances in breeding for quality chickens. World Poultry Sci J 61:373-381 (2005).

36 Brown SN, Nute GR, Baker A, Hughes SI and Warriss PD, Aspects of meat and eating quality of broiler chickens reared under standard, maize-fed, free-range or organic systems. Br Poultry Sci 49:118-124 (2008).

37 Murray JM, Delahunty CM and Baxter I, Descriptive sensory analysis: past, present and future. Food Res Int 34:461-471 (2001).

38 Castellini C, Berri C, Le Bihan Duval E and Martino G, Qualitative attributes and consumer perception of organic and free-range poultry meat. World Poultry Sci J 64:500-512 (2008).

39 Ponte PIP, Rosado CMC, Crespo JP, Crespo DG, Mourão JL, ChaveiroSoares MA, et al, Pasture intake improves performance and meat sensory attributes of free-range broilers. Poultry Sci 87:71-79 (2008).

40 Berri C, Variability of sensory and processing qualities of poultry meat. World Poultry Sci J 56:209-224 (2000). 